\title{
"DEViR": A Software for Determining and Visualizing Optimal Tree Felling Direction in Three-Dimensional Terrain
}

\author{
Burak Türkay $^{1}$ (D), Abdurrahim Aydın* \\ ${ }^{1}$ Düzce University, Institute of Science, 81620 Düzce, Turkey. \\ ${ }^{2}$ Düzce University, Faculty of Forestry, 81620 Düzce, Turkey.
}

\begin{abstract}
Felling trees, which is the basis of forestry activities, is dangerous and difficult work that needs to be performed carefully. These activities can affect forest workers' safety, damage the remaining forest, or reduce the value of the extracted product. Most of the accidents and injuries in forestry operations occur due to the trees not falling in the desired direction. Directional mistakes in tree felling processes or underestimating the criteria negatively affect the felling process, which may increase the damage on the product. In terms of life safety and property quality, not only the felling direction but also the safe escape route for the crew should be determined during tree felling. If these issues are ignored due to incomplete information or carelessness, they can cause serious safety problems. However, work safety can be improved through training programs. The primary purpose of this study was to develop a training tool, called "DEViR", to assist loggers for determination and visualization of the optimal tree felling direction. "DEViR" software was specifically designed to determine the ideal tree felling direction, as well as the escape route for the crew, and dangerous work zone according to safety rule of two tree in a 3D virtual environment. The sample application of the software was run considering artificially placed trees in a study area located in the city of Erzurum in Turkey. The findings of the sample application indicated that the use of this computer-aided simulation systems can provide felling direction solutions with high accuracy and details that cannot be done by a logger's decision. The results indicated that as the Digital Elevation Model (DEM) and orthomosaic resolution increases, "DEViR" can perform more realistic modeling and accurate calculations, but computation time and hardware requirement increase with increasing data size. Also, it was found that "DEViR" software is a good training tool as it presents visual material, animates the tree felling process interactively, and reflects the result of every decision to the user. Thus, it has great potentials to increase the performance of the loggers in training and daily felling operations.
\end{abstract}

Keywords: Felling Simulation, 3D Terrain, 3D Virtual Forest, Escape route, Safety

\section{Introduction}

Determining directional felling of trees in forests is very important decision in reducing residual stand damage (Naghdi et al., 2016) and avoiding unexpected accidents (Blomback, 2002; Tavankar et al., 2013; Newman et al., 2018; Nagao and Yamada, 2019; Tobita et al., 2019). "Directional felling" term refers to "felling towards a pre-determined lay, hence referred to as desired lay. Important objectives of directional felling include avoiding damage to potential crop trees, facilitating hauling, and avoiding damage to the tree fell" (Cedergren et al., 2002) Due to poor or incorrect decisions of practitioners, a tree can fall toward an unintended and unforeseeable felling direction. Being unable to predict which direction the tree will fall plays a significant role in many fatal accidents in forestry. Also, increased demand for logging and decrease in the number of trained crew due to aging, pose forest managers to train new crew within a short time. Thus, majority of the fatal accidents and tree damage occur while harvesting trees (Suhurtana and Yuniawati, 2019; Nagao and Yamada, 2019; Tobita et al., 2019).
Forestry work is more exposed to accidents than other industries due to rough terrain and difficult conditions (Garland, 2018). Due to high number of accidents, the most dangerous operation in forestry activities is tree felling. The main cause of fatal accidents in felling operations is the poor judgments on felling directions. This is the cause of a significant number of fatal accidents regardless of the size of the operations (Lindroos, 2006). Although safety in forestry activities is increasing day by day, the frequency of accidents remains constant. For example, a study conducted by Nagao and Yamada (2019) with 1000 forestry workers showed that the accident frequency was $30 \%$, which was 12.5 times higher than all other sectors. Also, it was pointed out that $33 \%$ of fatal tree accidents occurred due to unpredictable felling direction. According to Tobita et al. (2019), between 2000 and 2014 in Japan, fatal accidents by chainsaw felling were $41-69 \%$ of all fatal accidents annually in forestry. In developing countries, tree felling was almost half of the all forestry accidents (Blomback, 2002). In the U.S., rate of fatal injuries for logging workers was 136 out of 100.000 workers in 2016 (Newman et al., 2018). Furthermore, it was reported that 
tree felling is also closely related to numerous other nonfatal accidents (Lindroos, 2006).

Factors affecting tree felling with a chainsaw are crucial while analyzing fatal accidents. Tobita et al. (2019) determined 14 factors causing fatal accidents during tree felling. Five factors among others namely, i) contact between the felled tree and surrounding trees, ii) tree falling in an unexpected direction for any reason, iii) tree prevented from falling to the ground by obstacles, iv) felling performed in dangerous areas with insufficient distances for escape, and v) errors in judgment related to "escape position" and the delay in escaping factors reason for $65 \%$ of all fatalities (total 835 fatalities). Those factors are mainly related to determining felling direction and precisely guide escaping direction in case of necessity.

Tree felling and skidding works can cause severe damage to both log and the forest stand; thus, it is crucial to operate in the right direction and with the right technique in terms of continuity of productivity (Suhurtana and Yuniawati, 2019). In order to control the damage to the felled tree itself and the residual trees, maximum attention should be paid to determining felling direction in the planning phase (Cedergren et al., 2002). One of the key points to be considered in felling trees is felling trees toward the closest skidding path. That is important for persistence, an essential value in forestry operation. For the persistence, logging operation has to be with minimum damage to both soil and residual trees (Naghdi et al., 2016; Suhurtana and Yuniawati, 2019). Reducing the skidding time by felling trees towards the skidding path with a felling process in the right direction prevents significant damage to the residual trees, young generation, and the environment (Naghdi et al., 2016).

Residual tree damage increases with increasing diameter at breast height (DBH) of the felled trees (Jackson et al., 2002). Residual trees with smaller DBH is exposed to the damage mostly due to skidding of felled trees (Naghdi et al., 2007). Shormag (2009) reported that in a felling operation, as the first step in wood production, proportion of the damaged residual trees were about 17 to $20 \%$ (on average) and $33 \%$ of these trees were 50 to $70 \mathrm{~cm}$ in diameter. According to Bruening (2017), the damage level to the residual stands could be reduced by using the correct felling method and planned directional felling angle (Naghdi et al., 2016).

Directional felling error (DFE) have been studied recently by many researchers (Krueger, 2004; Naghdi et al., 2016; Bruening, 2017; Nikooy et al., 2013). DFE occurs when actual direction of felled trees is not compatible with planned direction (Cedergren et al., 2002). In a study conducted in Sarawak-Malaysia, 26\% of the felling operations went out of the desired direction. It has been observed that DBH causes about a quarter of these DFEs (Bruening, 2017). The findings of the similar studies conducted by Krueger (2004) and Naghdi et al. (2016) also support this argument. However, Cedergren et al., (2002) stated that the combination of "tree size" with "ground inclination" parameters explain 54\% of DFE.

Since many workers in the forestry sector have little or no training (Garland, 2018), a 3D simulation software that can be used to improve workers' skills will increase the quality and permanence of training activity and help visualization and therefore better understanding of the process. Also, live monitoring of the intervention to be made and observing the result after the procedure will affect decision-making success and prevent potential loss of life and property. McGaughey (1997) has established a stand visualization program suggesting that $3 \mathrm{D}$ visualization will provide significant benefit in the training of forest workers and the implementation of forestry operations. Afterward, although there were a few more attempts in this direction, most of the known stand visualization software was not available, and many of them were canceled or remained inadequate in terms of technology or functionality.

In this study, 3D interactive software, called "DEViR", with advanced graphics quality was developed to apply tree felling operations using a real coordinate of the field. Apart from calculating the most appropriate felling direction, it presents the damage level for all directions, the escape route, the risk zone according to the two tree rule, and the animated felling moment with gravity effect animation. It provides detailed information about the felled tree, and extracted and residual volume of the trees in the stand. The software is straightforward to use and understandable with a simple interface. It also helps the user to select the tree to be felled, as it interactively displays the information, such as diameter, height, species, age, crown width, and volume of the trees on the screen.

\section{Material and Methods}

The software developed in the study was introduced in six sub-stages using a sample application. In the application, "DEViR" was run with a data set consisting of artificially placed trees with real world coordinates. The sample field studied was taken from the province of Erzurum in Turkey using drone and photogrammetry techniques. While generating data set, attention has been paid to the details encountered in practice. Accordingly, there were details in the field such as road network (highway) and stream where the trees are not preferred to fell over.

\subsection{Introducing the "DEViR" Software}

DEViR was designed for training tree felling crew and forestry students to perform felling operations correctly and safely, to simulate operations with computer graphics, identify risks, design necessary plans and precautions. The developed program includes tools to analyze all the directions where the tree can fell, to determine the escape route of the crew who cut the tree and to determine the area that is in danger during the felling process. 
"DEViR" was developed in Python programming language using basic libraries such as "numpy, pandas" which are open source code, without using any paid APIs, libraries, programs, or tools that require a license. It is an independent software developed for the Windows operating system, consisting of many interconnected script files, functions and data structures (such as stored data for trees, color settings, and triangulated irregular network data). The external intervention should be simplified as much as possible to make its complex structure easy to use and understand. For this purpose, many calculations / transactions in the program (Explanations about background processes will be made in the next sections) were automated for the user. A simple workflow was presented to the end-user with a simple GUI (Figure 1).

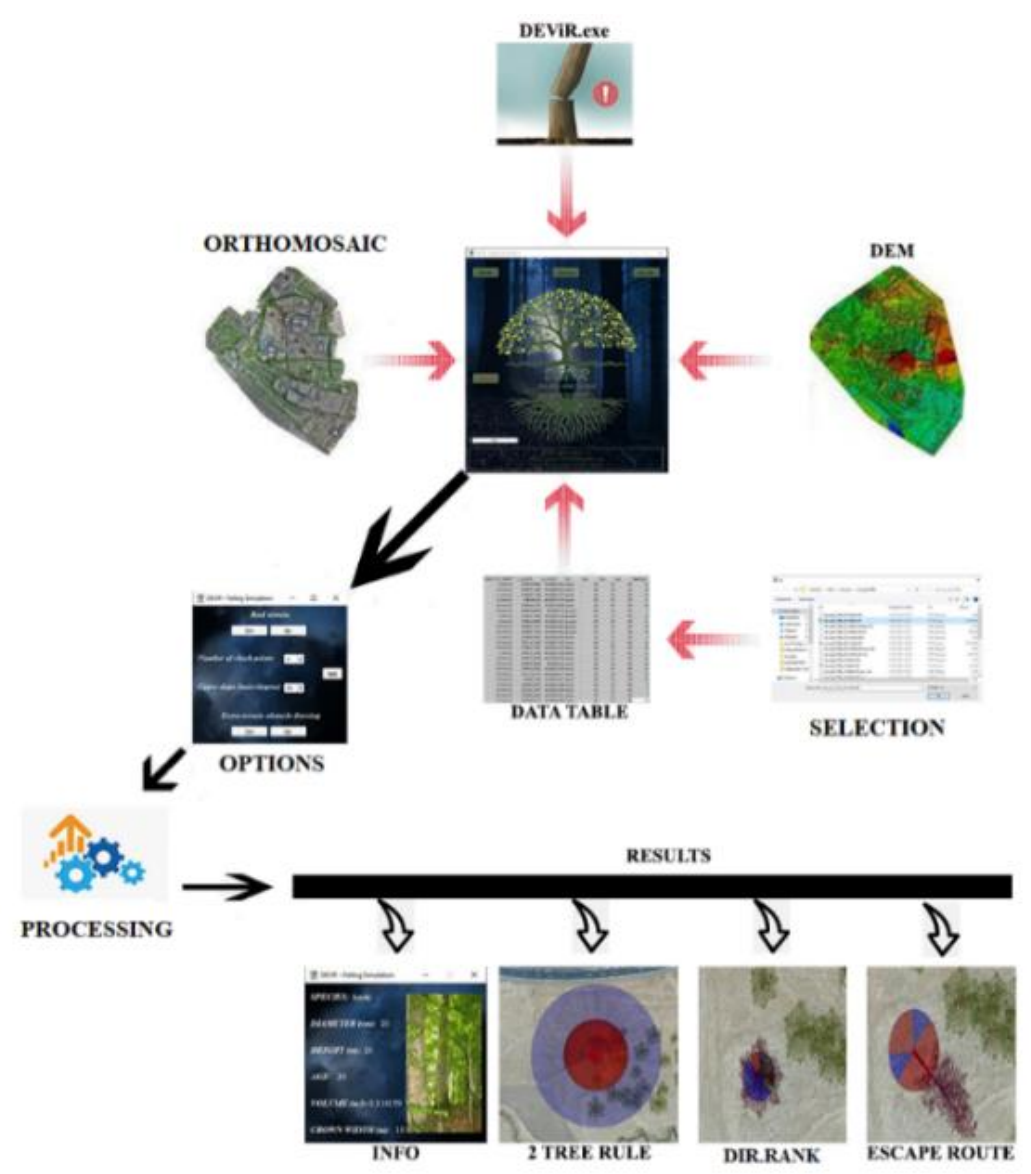

Figure 1. Work flow chart realized through GUI

The software is ready to run after installation. With "Devir.exe", the software is run, all necessary precursor modules (e.g., analysis, file reading, import tools) are activated, and the GUI is started. In the first stage of the program, the GUI has buttons to start data entry and analysis, and informative text section for warnings and reminders, and an indicator bar for process status. The interface, simple and user-friendly, has been designed with the precaution that will not allow user-error as much as possible (e.g., doing the operations sequentially) (Figure 2).

The screen for the data selection was generated as a standard file selection system. The data table containing the required tree information, DEM, and orthomosaic (Figure 3) is selected with the help of this selection system in the GUI.

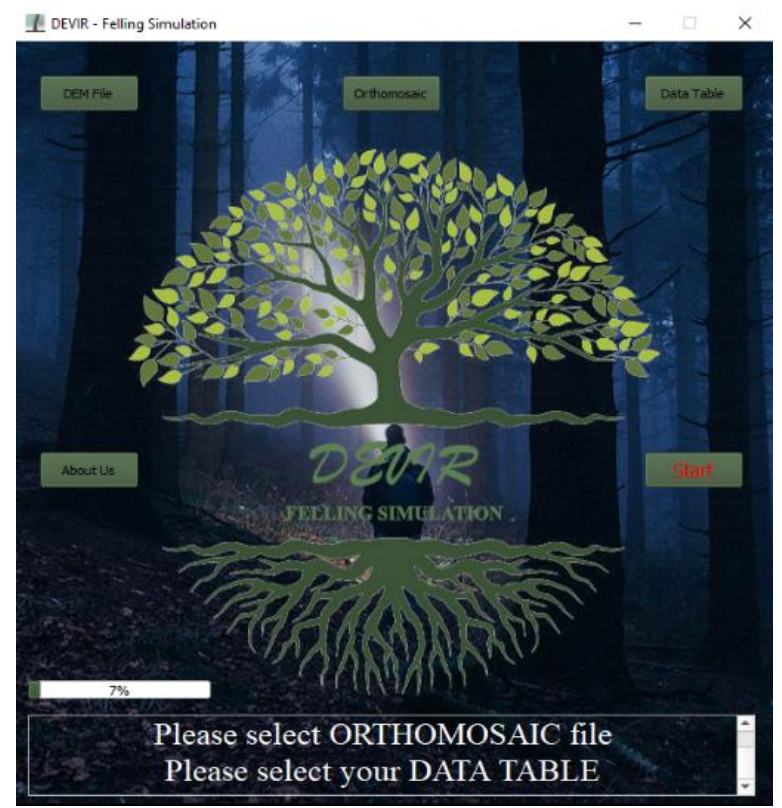

Figure 2. GUI main screen 


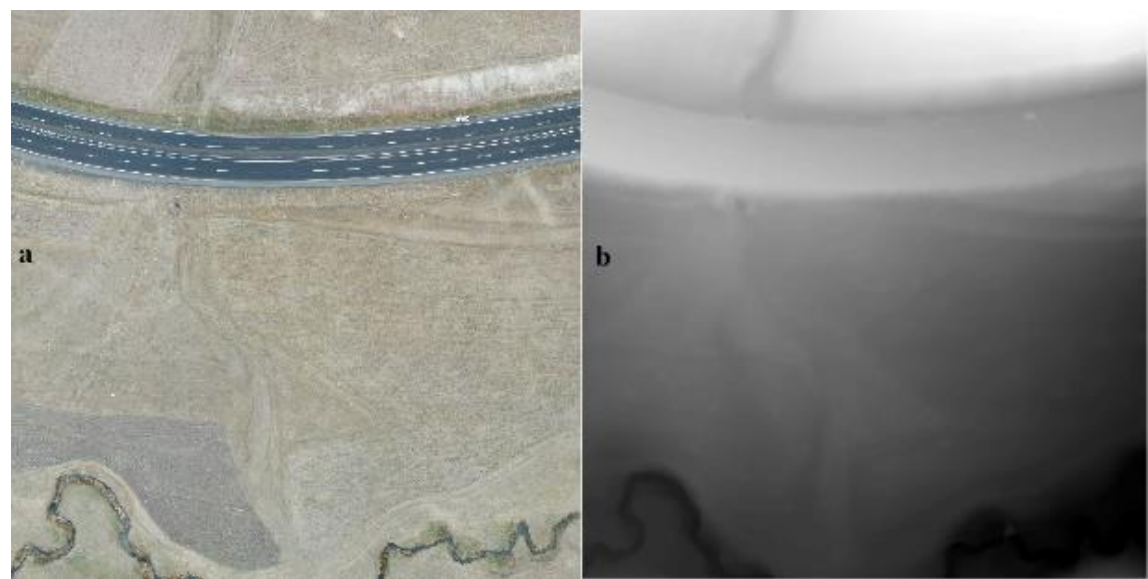

Figure 3. The orthomosaic data (a) and DEM (b) used in the sample application

Selected DEM and orthomosaic data should have ".tif" extension and the table containing tree information should have ".csv" extension. The orthomosaic and DEM data must be digitized and in the same projection. The software also supports using image data of any format (jpg, png, etc.) instead of orthomosaic but it is recommended to use orthomosaic to model the same appearance as the terrain. However, the quality of the DEM/orthomosaic used directly affects the surface appearance/quality and processing/computation precision. Thus, it is suggested that the DEM resolution should not be more than $2 \mathrm{~m}$.

During the analysis period beginning with the "Start" button, information about the data and the calculations is presented to the user in the information panel. The completion of the process is followed by the options screen (Figure 4). On this screen, it can be selected whether the area to be worked on is real or artificial, from how many points the felling tree will touch the ground (for collision analyzis), risky slope threshold definition, and draw negative felling points (NFP).

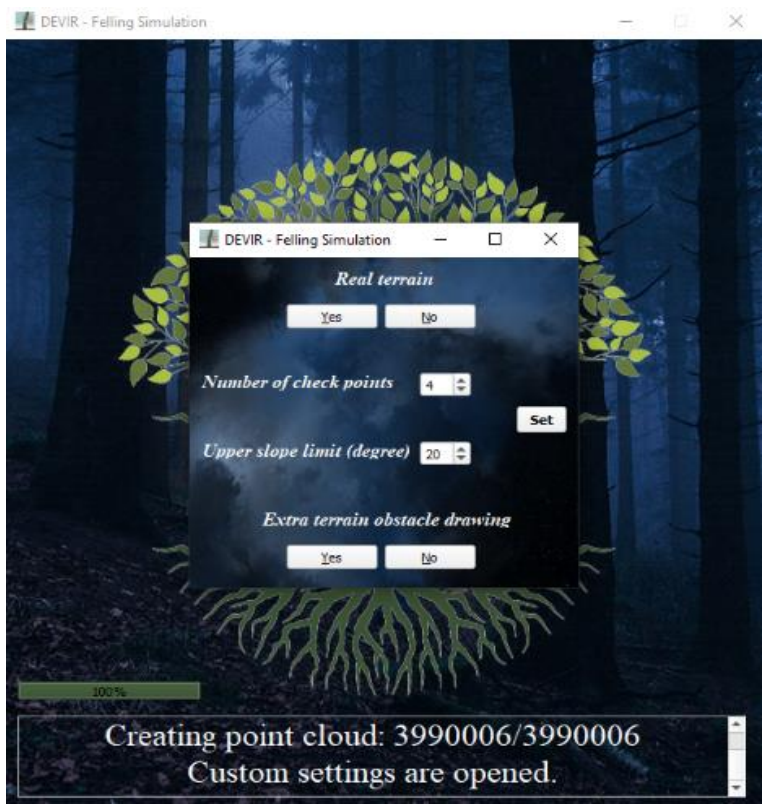

Figure 4. Option screen
After saving the settings (for temporarily in the RAM), the next process is to create the surface and tree models and visualization of the 3D environment. At this stage, two screens appear (Figure 5), one is the simulation screen and the other is the information screen. With the opening of the simulation screen, the analysis can be starts and four outputs, Info, 2 Tree rule, Dir. Rank, and Escape Route, can obtained as a result (as shown in Figure 1). "Dir. Rank" in the workflow presents the riskhazard level of the directions. All operations are performed on simulation screen while the information screen provides general picture for the species, species name, diameter, height, age, volume and crown information about the selected tree (appears as maroon on the screen after the tree is selected) (Figure 6).

For various reasons, there may be areas where it is not desired to fell the tree (NFP). These regions must be specified before starting the felling analysis. It can be specified by drawing with the tool developed for this process. If there is more than one NFPs for the felling process, user can determine location of multiple NFPs by drawing. The operation of this tool, explained in the sections 2.4, can be seen in Figure 7. The volume information of all trees in the field can be calculated automatically by the software. Thus, by removing the tree to be felled, the volume information of "extracted / residual material" can also be presented in the information text section.

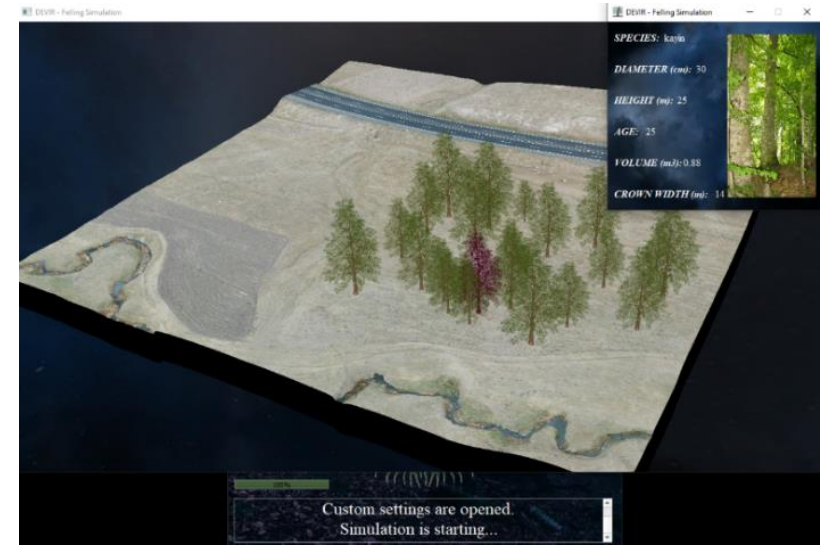

Figure 5. The main simulation screen and information panel 


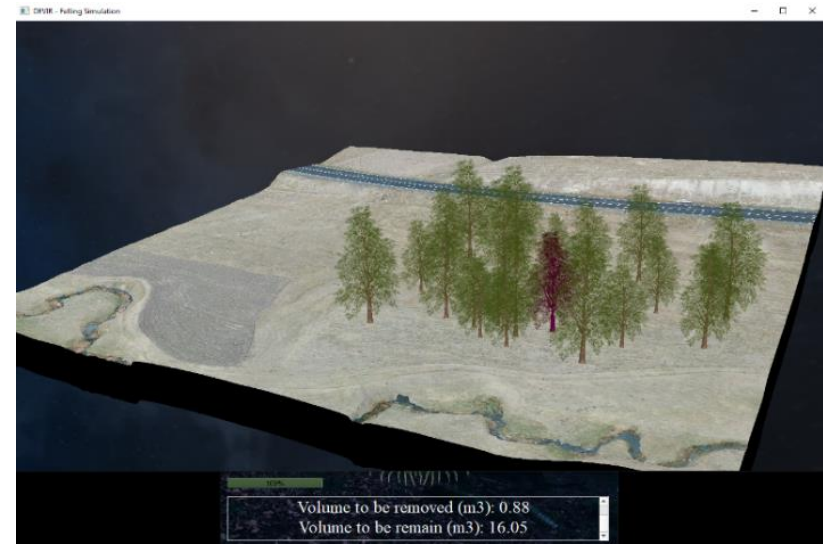

Figure 6. View of the selected tree on the stand

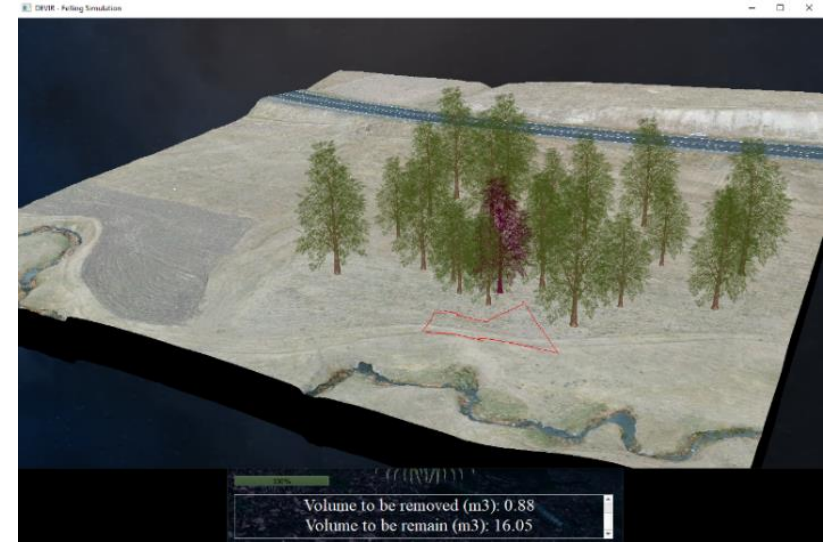

Figure 7. Drawing of special obstacle areas by hand and extracted/residual material

After all the procedures are done, RFD (ranking for felling direction) analysis is performed. Then the result is visualized and the user has an opportunity to choose the direction of the felling (Figure 8). If the user prefers, this selection can also be made by the "DEViR". At this stage, the user can see both the optimum felling direction and the most unfavorable felling direction. The result of the risk area analysis based on the safety rule of two tree is displayed in Figure 9.

The escape route analysis, which is designed for workers to escape from the field with the least risk during tree felling and the view of the felled tree, is shown in Figure 10. Escape directions are shown in blue and the risk zone in red in "DEViR" screen. With the interaction of the mouse and keyboard, "DEViR" allows to travel in the forest as desired, to look from the desired angle or from the desired location, to take cross-section and screenshot, and to present the remaining forest view by deleting the felled tree from the field.

\subsection{D Terrain Model and Stand Visualization}

In order to perform tree felling operations, forest and terrain model must be generated in a 3D computer environment. For this reason, the developed software needs the orthomosaic and DEM data of the working area. The requested DEM selected in the first phase of the software and must be in .tiff format. The height information of each point of the terrain was extracted from DEM.

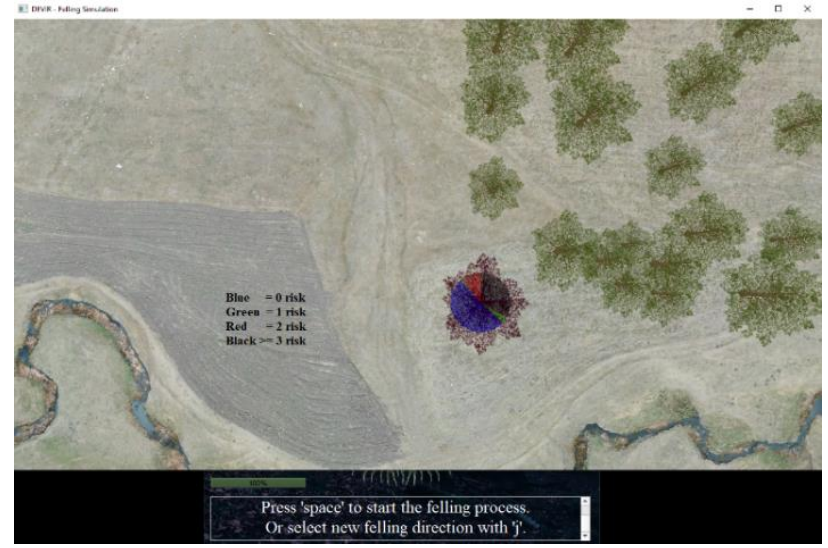

Figure 8. Indication of the obstacle-risk levels of the directions

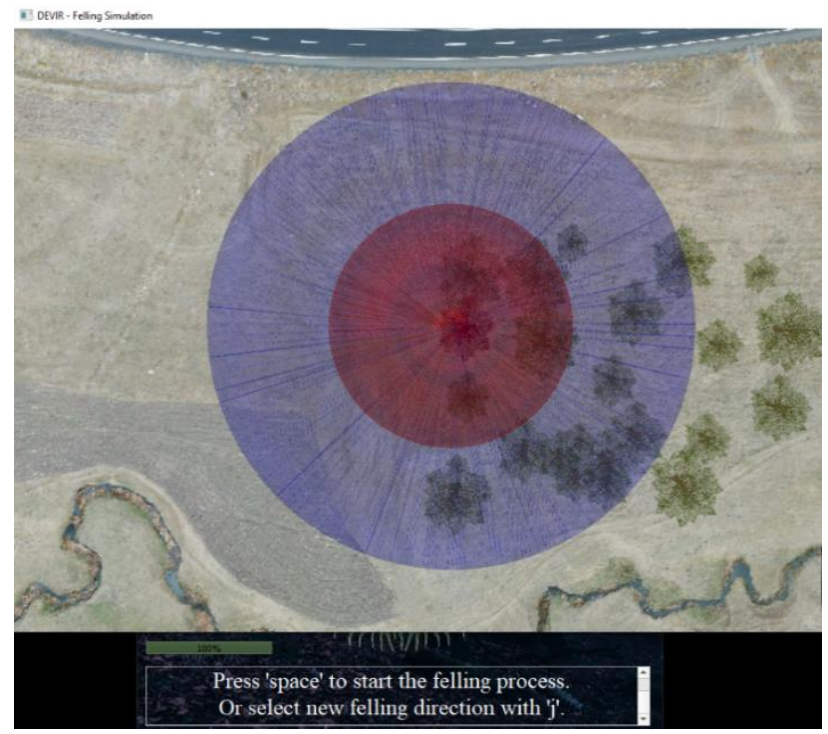

Figure 9. Risk zone analysis in the field according to the two tree rule

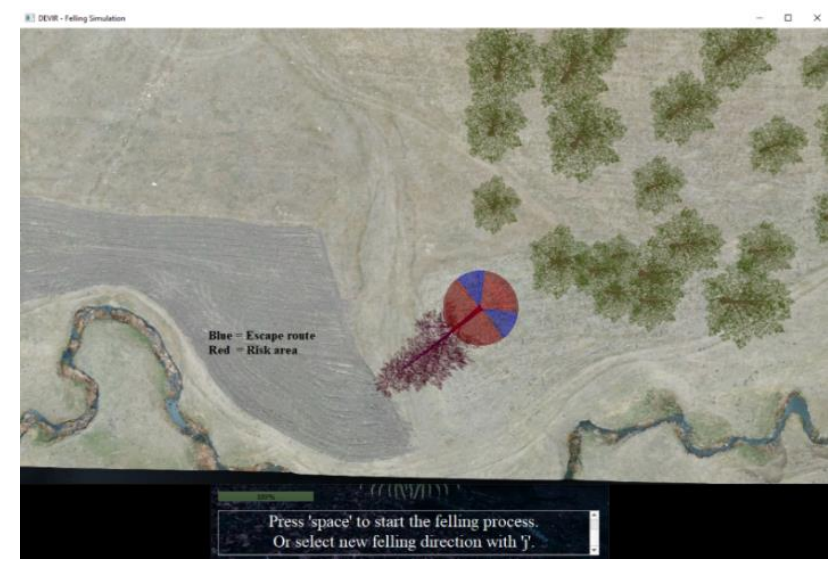

Figure 10. Escape route and visualization of felled tree

$\mathrm{X}$ and $\mathrm{Y}$ position information was added to this height information via DEM data and stored as a matrix in ram as points that can be located in $3 \mathrm{D}$ space. In this way, depending on the size of the DEM, a large point matrix (point cloud) is produced. Next, triangulated irregular network (TIN) was produced by combining the points in triangular, and the terrain surface with similar to real one was generated by placing the orthomosaic data on this TIN. 
After the terrain surface was produced with DEM and orthomosaic, virtual forest stand should be developed. In order to generate the stand, the data table in ".csv" format containing the information of the trees must be given by the user. The information requested in the data table are as follows; " $x, y$ " (m-float, it refers coordinates of trees), "species" (str), "diameter" (cm-int, at breast height), "height" (m-int), "age"(int), "crown width"(m-float). Then, the software reads and analyzes the table, designs the tree model according to its species and characteristics, and placed to the corresponding area on the 3D terrain surface according to the location information in the data table. Visualization is provided by drawing them to the screen with the help of a graphic card.

\begin{tabular}{|c|c|c|c|}
\hline $\mathbf{R}$ & G & B & A \\
\hline 0.5 & 0.9 & 0.1 & 1 \\
\hline 0.5 & 0.9 & 0.9 & 1 \\
\hline 0.1 & 0.6 & 0.7 & 1 \\
\hline 0.9 & 0.5 & 0.5 & 1 \\
\hline 0.3 & 0.8 & 0.5 & 1 \\
\hline 1 & 0.9 & 0.4 & 1 \\
\hline 1 & 1 & 0.3 & 1 \\
\hline
\end{tabular}

\section{$\mathbf{X}$}

\begin{tabular}{|c|c|c|c|}
\hline $\mathbf{R}$ & G & B & A \\
\hline 0.9 & 0.0 & 1 & 1 \\
\hline
\end{tabular}

\subsection{Selecting Tree to be Felled}

Figure 11. Color data rearrangement depending on selection

With the selection of the tree; the information of the related tree taken from the data table (user provides these data in the first phase), the volume information determined as a result of the calculations and the picture about the species are displayed simply on the new opened screen (information screen). This information screen consists of diameter (at breast height), height, age, volume, crown width, species name, and a sample picture. The volume of the selected tree $\left(\mathrm{V}_{\text {tree }}\right)$ was calculated based on the Equation 1.

$V_{\text {tree }}=\pi\left(\frac{R / 100}{2}\right)^{2} H * f$

where $\mathrm{R}$ is diameter in $\mathrm{cm}$ provided by the user, $\mathrm{H}$ is the height in meters provided by the user, and " $\mathrm{f}$ " represents the shape coefficient (taken as 0.5). The total volume of the remaining in the stand $\left(\mathrm{V}_{\text {remain }}\right)$ was calculated by using the formula in Equation 2 where $\left(\mathrm{V}_{\text {extracted }}\right)$ is the volume of the tree to be felled and $\left(\mathrm{V}_{\text {alive }}\right)$ is the individual tree volume in the stand.

$V_{\text {remain }}=\left(\sum_{n=1}^{\infty}\left(V_{\text {alive }}\right)\right)-V_{\text {extracted }}$

\subsection{Determination of Negative Felling Points (NFP)}

The tree selected for felling should be determined in the directions that it is desired not to fell over. The directions that are not planned for tree fell are named as negative felling direction/point. Areas where trees are not to be fallen on the stand are generally regeneration areas, protected areas for any reason, and artificial areas such as areas where energy transmission lines are located. The developed tool marks the places where these
In order to access the information of each tree on the 3D terrain or to perform a felling operation on a tree, the tree must be first selected. Since the tree selection process is basically a mouse interaction, it is appropriate to use the 3D object interaction logic. In the tree selection process, the user moves the mouse cursor to the tree and selects the desired tree with the mouse by left click. In order to distinguish the selected tree, the color matrix of the tree is transformed with a $1 X 4$ matrix containing the values $[0.9,0.0,1,1]$ as in Figure 11. In the figure, "B" stands for blue, "G" for green, "R" for red, and "A" for alpha. Alpha, red, green and blue band values are in the 0-1 range. The color appears according to the composition of these bands. After this process, only the color of the selected tree is changed, which makes the selection process more understandable.

areas are located. In the working principle of this tool; two points selected by mouse interaction are saved in a list, then a line called "boundary line" is drawn between these two points. This line represents negative felling points, in other words restricted directions that are not preferred to fell over, and it can be used in many forms such as square and triangle.

\subsection{Ranking for Felling Direction (RFD)}

After generating NFPs, it should be calculated and checked whether the tree to be felled will come into contact with at least one of the NFPs during the felling operation. Also, the tree to be felled must not touch the trunk and crown of the trees remaining in the stand that can be found in the direction of the fall. This is important for the quality of the product to be extracted, reducing the damage of trees remaining in the stand, and for the safety issues, directly affecting worker's safety. Hence, the directions of the tree to be felled without hitting other trees needs to be determined. A "Collision Detection System" (CDS) has been designed to prevent the felled tree from hitting the remaining trees.

CDS is a system used in computer graphics, from physics simulations to computer-based designs (Jimenez et al., 2001). In collision detection, the distance between the tree to be felled and the remaining tree should be checked and determined (Equation 3). In the distance control formula, $\vec{x}, \vec{y}$, and $\vec{z}$ represents the difference between the $x, y$, and $z$ values of the two trees. Distance control is also performed for the tree to be felled and NFPs. 
$x=\sqrt{x^{-2}+y^{2}+z^{-2}}$

After determining the distance, the crash occurs when the height of the tree to be felled is equal to or longer than the calculated distance. Otherwise, tree crash will not occur. This analysis is made with the "Equation 4" where, $T_{\text {height }}$ represents tree height and $p x_{w}$ shows horizontal pixel resolution.

$x \leq T_{\text {height }}+\left(\frac{p x_{w}}{2}\right)$

The directions that comply with the Equation 4 output are declared as restricted directions (the direction in which the tree is not intended to fell). The direction of the relevant tree with respect to the tree to be felled should be determined in terms of angle. This process is calculated according to the Equation 5.

$H=\arctan (\overrightarrow{\mathrm{x}}, \overrightarrow{\mathrm{y}}) *\left(\frac{180}{\pi}\right)$

In determining the situation of whether felled tree hits the branches of the residual trees or not, the approach to determining the case of hitting the trunk is applied. The "H" angle in this analysis (analysis of whether felled tree hits the branches of the residual trees or not) is calculated differently from the " $\mathrm{H}$ " angle in the approach used to detect the felled tree hitting the trunk of the remaining trees. In order to calculate this angle, the branch boundaries or the crown boundary in the plan view are taken into calculations. The area of 1.5 times the distance of the crown boundary to the trunk was determined in the angle calculation in order to determine the danger zone, and then the position values were calculated. A 1.5 coefficient is used for generating a safe buffer zone (Figure 12).

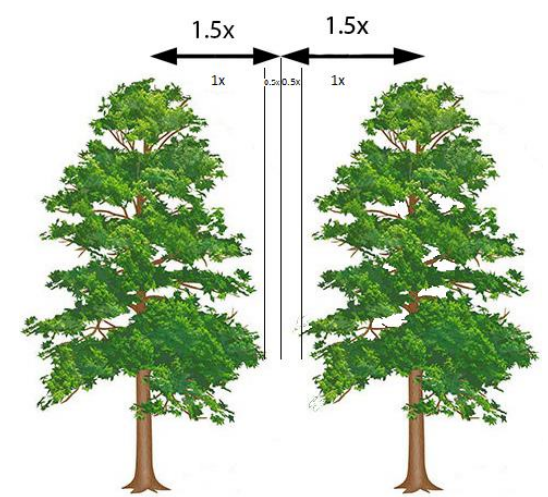

Figure 12. The danger zone as 1.5 times safe buffer zone

There should be no abrupt changes in inclination that may cause the tree to break in the felling direction. The maximum acceptable slope limit (threshold value), which will not cause the tree to break, can be adjusted from the settings screen. If the user does not specify a maximum acceptable slope limit, this value is taken into calculations as $20^{\circ}$ degrees (Figure 13). $20^{\circ}$ degrees is the default value defined in the program for this calculation of slope changes.
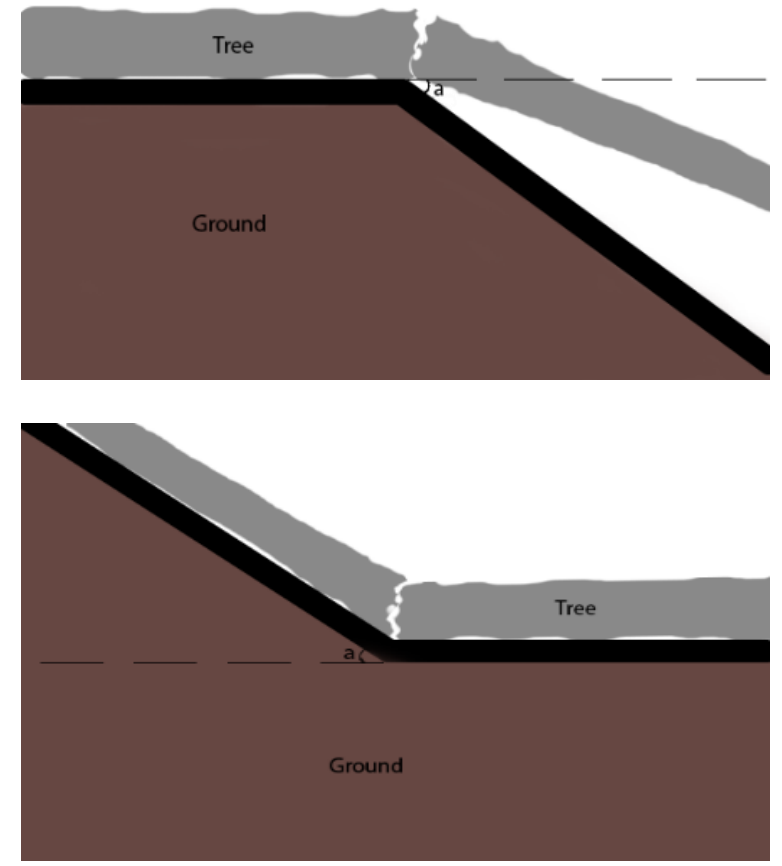

Figure 13. The effect of slope fracture on a felling tree ('a' refers to slope)

Detection of abrupt slope change starts with determining the points (it is taken as "points" because tree touches the surface in one direction at more than one point) where the tree's trunk to be felled can touch on the ground according to the Equation 6. The tree is divided into a number of sections, determined by the user. Thus, it is determined whether each section touches the ground in the relevant direction at the end of the felling. The main criterion for the user to determine the number of sections is computer power. The user can specify as many sections as he/she wants according to the computer power. These sections are positioned at equal intervals according to the height of the tree. In the Equation 6, $\mathrm{H}$ represents the total length of the tree (from data table in ".csv" format), and $K_{\text {test }}$ how many tests (sections) is to be made, and $\mathrm{k}$ represents which test is to be performed at that time. $\dot{I}_{\text {height }}$ indicates the length / height of the relevant section of the tree. Then, the $x$ is calculated for the distance between the surface point and the tree using Equation 3 is evaluated in Equation 7. Equation 7 is used to determine the relationship between a slope information or a slope-related surface point and the relevant section of the tree.

$\dot{\mathrm{I}}_{\text {height }}=\frac{k}{K_{\text {test }}} * H$

$\dot{\mathrm{I}}_{\text {height }}+\left(\frac{p x_{w}}{2}\right) \geq x \geq \dot{\mathrm{I}}_{\text {height }}-\left(\frac{p x_{w}}{2}\right)$

According to Equation 8, the values obtained from the slope calculation made with the place where the tree might touch are evaluated as a whole. If threshold value exceeded between sections, the direction of the relevant place relative to the tree is calculated with Equation 5 and defined as the "improper felling direction". When the tree is divided into sections, the slope of the point 
where the upper limit of each section intersects on the ground is calculated with the formula in Equation 8. In this formula, first, the elevation of the tree's top above sea level is determined by the height of the tree added to the ground elevation of the tree then, the aforementioned $\overrightarrow{\mathrm{z}}$ value is found by subtracting the elevation of the relevant ground from the elevation of the top of the tree. In the same formula, $\mathrm{x}^{\overrightarrow{ }}$ defines the distance between relevant ground and tree.

Apart from the abrupt change in slope, the general slope of the surface is also analyzed for to calculate the entire slope of each direction in which it may fell over. If the overall calculated slope for the surface is above or equal to the threshold slope value chosen by the user, the surface in this direction is defined as dangerous (See Figure 13).

slope $=\arctan (\overrightarrow{\mathrm{z}}, \mathrm{x}) *\left(\frac{180}{\pi}\right)$

After the analysis is completed, all dangerous directions were combined and scored. Each hazard situation was scored separately (e.g., if the tree to be felled in the calculated possible felling direction will touch 3 trees, the hazard score for all three trees is taken into account). Therefore, having more than one danger in one direction increases the score of the relevant direction. Since the trunk is the main factor and the damage to the trunk will also damage the crown, the contact point to the trunk was scored as two, while each remaining element was given one point. The direction with the highest total points indicates the most unfavorable direction for the tree to fell.

After the RFD analysis, the danger score of the directions was determined and visualized. Accordingly, when there is no dangerous element in the direction to be felled, and, when the danger score is " 0 ", the relevant direction is shown in blue. When the danger score is 1 , it is shown in green, when it is 2, it is shown as red, and when it is 3 and above, it is shown in black by default. In this representation, a circular chart is created and the decision-making process of the user is supported. The user can choose the direction intended the tree to be felled by clicking. Based-on the user's preference, it is possible to choose the direction of felling with any danger score.

\subsection{Escape Route Determination and Risk Area Visualization}

It is important to plan the escape routes of practitioners to avoid a possible danger during the felling phase. The $90^{\circ}$ degrees right and left of the planned (determined) felling direction of the tree and $45^{\circ}$ degrees left and right of the angle opposite to the felling direction are defined as the high-risk zone (Anonymous, 2016). The remaining directions should be planned as an escape route (Figure 14).

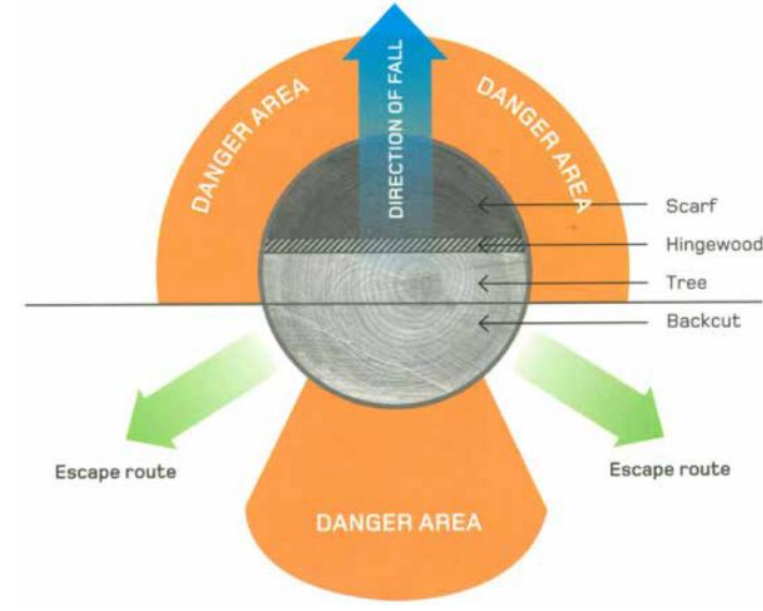

Figure 14. Escape route (Anonymous, 2016)

Except for the crew (worker) who will fell the tree, nobody else should be present in the area covering two tree-length radius for safety reasons (Anonymous, 2016). As a rule, the tree to be felled is considered the center, and the area at a tree-height distance is a high risk zone. The area that is twice the height of the tree to be felled is a medium-high risk zone, but if possible, nobody should be present (Figure 15). In the figure, "1" represents one tree height and high risk zone, "2" represents two tree height and medium-high risk zone. With "DEViR", the risk area has been visualized by showing the whole field within the distance of a tree height in red and the field at the distance of two-tree height in blue.

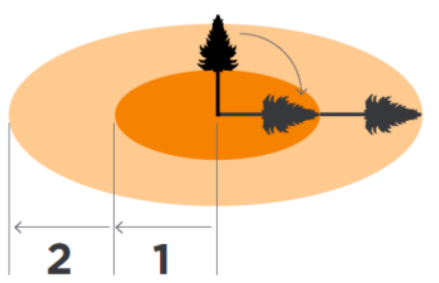

Figure 15. Two tree rule (Anonymous, 2016)

\section{Results and Discussion}

In this study, "DEViR" software that enables tree felling applications and analysis in 3D environment was developed. While the study by Cedergren et al. (2002) showed that directional felling can be used even in steep sloping tropical rainforests to save trees from damage caused by felling, our study also aimed to maximize the benefit of directional felling and its analysis and presentation in the most effective way.

3D visualization technique with orthomosaic has been thought to be the most effective method because; with computers add a new dimension to the visualization world (Strong and Smith, 2001), 3D visualization started to spread rapidly and the use of real pictures in computer graphics has attracted great attention as it provides more advanced photo-realistic image synthesis (Naemura et al., 2001). In the sample application made in this study, it was seen that the surface model produced with orthomosaic was very realistic. In addition, the case study has shown that this realistic visual also facilitates 
perception and enables to create more accurate plans. According to a study, the average increase in knowledge was $40 \%$ higher in the visualized class than in the class with plain text (Lis, 2014). Despite the advancement of technology, few studies have explored the possibility of using 3D visualization techniques to represent real data of forest structure (Kantartzis, 2018). Previous studies showed that very few software could be implemented in forestry for visualization, such as "Stand visualization system" (McGaughey, 1997). However, these systems only offer general designs that represent the field, do not visualize every point the same as in the real field with real data, and the graphic quality is insufficient.

"DEViR" software is able to produce high graphic quality images, depending on the quality of the DEM and orthomosaic, and can achieve a considerable success in tree felling operations. Thus, it has been seen that 3D visualization will provide great benefit for the training and practices of forest workers. However, even trained fellers perform felling operations with a deviation from the planned direction, and they ignore the slope, residual damage and possible effects. In general, although operations are performed with basic logic and assumptions or based on experience, these may not always give accurate results. In this case, a deviation due to incorrect direction planning will negatively affect the result. Visualizations of silvicultural operations provide important feedback in the forestry operations and help convey the applied procedures to the authorized persons (McGaughey, 1998). Similarly, the "DEViR" software ensures that the calculations are made correctly by understanding the felling operations better. Thereby, it reduces the aforementioned probability and gives an advantage in explaining the planned transaction to someone else.

It would be mistake to use a single mathematical logic in the tree felling operations. For example, the fell of single trees or the fall of edge trees is different from the fell of the rest of the trees within the stand. Therefore, the calculation of their felling directions will be complex and show differences mathematically, as well. The examining the relation between the trees in the stand individually and collectively with the tree to be felled becomes important, increasing the accuracy of the decision. According to Cedergren et al. (2002), when considering the effect of the deviation due to ground slope and tree size, more care should be taken while felling trees on slopes. If the slope is steep and tree size are very large, it should be considered not to fell the tree. This shows that the slope and its fractures are very important in the felling process, but it is not paid enough attention in practice. It is not possible to calculate many alternatives in detail without computer support. Since one of the main parameters in the "DEViR" software is analyzing aforementioned slope relationships, the obtained results are more precise and accurate. Extreme obstacles (NFP) in the felling area can also affect the felling, so additional work is required. However, in practice, the relationship between the tree to be felled and extreme obstacles cannot be fully resolved due to the application of observational decision-making logic. In the "DEViR" software, due to generating a drawing tool to show the extreme obstacles (NFP), the relation of the obstacle or problem with the tree is calculated more accurately and included in the parameters.

Most of the mistakes in tree felling are caused by insufficient/poor quality in training and planning. According to the study of Cedergren et al. (2002), although felling operations deviating from the planned direction is a major safety problem, there is an opportunity to improve occupational safety through training. The "DEViR" software, developed with this aim in mind, is a good training tool as it provides visual material for use, performs the felling operations interactively, and reflects the result of every decision to the user. The development and use of such 3D virtual training or practice software are essential for increasing the knowledge and skill of interest groups in forestry applications.

The software developed so far for visualization purposes is generally not designed for forestry operations, including tree felling, but are generally developed for determining the capacity of forest stand or land and their visualization. Some of the software that has been developed since 1995 are Utools, Uview, and Truflite (Ager and McGaughey, 1995; Adamiker, 1997). Apart from these, there are some initial applications related to forestry that are still accessible, such as "smart forest visualization tool" (Uusitalo and Kivinen, 2000), "Stand Visualization System-SVS" (McGaughey, 1997). In addition, most of the developed software does not offer the opportunity to visualize the forest or felling trees on a 3D terrain in real-world coordinates. They cannot produce quality tree models along with the terrain model, and the positions cannot be matched precisely with the actual area. In none of these studies, the felling process cannot be performed with the environmental evaluation based on the aforementioned parameters on the real earth model and the tree with real location.

\section{Conclusion}

Tree felling is at the core of forestry activities. These activities, which are made for production and maintenance purposes, need to be done carefully. Determining the direction of felling in cutting operations is critical for the safety of life and property. Therefore, the primary expected outcome of this study is to develop a decision support mechanism to determine the direction of felling. "DEViR", a software developed for this purpose provides a 3D virtual forest environment with DEM, orthomosaic and tree information (coordinate, species, diameter, height, age, crown width). "DEViR" is a Python software specially developed for determining the ideal (optimal) felling direction in trees. The software calculates and visualizes the damage level of all aspects valid for the tree to be felled by identifying and scoring hazard/risk aspects 
with the NFP and RFD stage, respectively. In this way, the user is able to make a decision by predicting the possible results after the felling. "DEViR" also uses the rule of two-trees to identify and visualize hazardous areas for those working in the field where tree will be cut. After determining the danger zones in the whole area, it is also important to determine the escape route for the fellers to escape while the tree falls in the felling area. The escape route is determined in a way that $180^{\circ}$ for the felling direction of the tree and $90^{\circ}$ intervals for the opposite direction are dangerous. When examining the results of this study, it is observed that making plans and training with this software ensures an increase in work and fellers safety, prevents damage to the residual / felled trees. Besides, using the software as a training tool has great potential for associating theoretical information within practice. Therefore, based on the promising results of the "DEViR" software, it is recommended to be used in training, theoretical and practice stages.

\section{Ethics Committee Approval: N/A}

Peer-review: Externally peer-reviewed.

Author Contributions: Concept: A.A.; Design: A.A. and B.T.; Supervision: A.A.; Resources: B.T; Data Collection: A.A. and B.T.; Analysis: B.T.; Literature Search: A.A. and B.T.; Writing Manuscript: A.A. and B.T.; Critical Review: A.A.

Conflict of Interest: The authors have no conflicts of interest to declare.

Financial Disclosure: The authors declared that this study has received no financial support

Thanks: The authors would like to thank to Assist. Prof. Dr. Zennure Uçar for her helpful advice on the language editing of the manuscript.

Cite this paper as: Türkay, B., Aydın, A., 2021. "DEViR": A Software for Determining and Visualizing Optimal Tree Felling Direction in Three-Dimensional Terrain. European Journal of Forest Engineering, 7(1):111.

\section{References}

Adamiker, M.D., 1997. TruFlite-3D terrain visualization. The Association of American Geographers (AAG) newsletter 32(8).

Anonymous, 2016. Treefelling best practice guide. Forest owners association, pp. 29-35.

Ager, A., McGaughey, R.. 1995. Utools. http://forsys.cfr.washington.edu/Software/UTOOLS/ readme.txt (Accessed: 26 April 2021).

Blombäck, P., 2002. Improving occupational safety and health: the International Labour Organization's contribution. RAP publication (FAO).
http://www.fao.org/3/AC805E/ac805e01.htm (Accessed: 26 April 2021).

Bruenig, E.F., 2017. Conservation and management of tropical rainforests. An intergrated approach to sustainability. $2^{\text {nd }}$ edition. $C A B$ International, $p p$. 401.

Cedergren, J., Falck, J., Garcia, A., Goh, F., Hagner, M., 2002. Feasibility and usefulness of directional felling in a tropical rain forest. Journal of tropical forest science, 14(2):179-190.

Garland, J.J., 2018. Accident reporting and analysis in forestry: guidance on increasing the safety of forest work. Forestry working paper no 2, Rome, FAO.

Jackson, S.M., Fredericksen, T.S., Malcolm, J.R., 2002. Area disturbed and residual stand damage following logging in a Bolivian tropical forest. Forest ecology and management, 166:271-283.

Jimenez, P., Thomas, F., Torras, C., 2001. 3D collision detection: a survey. Computers \& Graphics, 25(2):269-285.

Krueger, W., 2004. Effects of future crop tree flagging and skid trail planning on conventional diameter-limit logging in a Bolivian tropical forest. Forest ecology and management, 188:381-393.

Kantartzis, A., 2018. A visualization tool for forest landscape using open software. International journal of Engineering Research and Development, 14 (07):23-40.

Lindroos, O., 2006. Efficiency and Safety in Selfemployed Family Forestry. Doctoral thesis, Swedish university of agricultural sciences, Umea.

Lis, R., 2014. Role of visualization in engineering education. Advances in science and technology research journal, 8(24):111-118.

McGaughey, B.. 1997. Visualizing forest stand dynamics using the stand visualization system. In: Proceedings of the 1997 ACSM/ASPRS Annual Convention and Exposition; April 7- 10, 1997; Seattle, WA.

Bethesda, MD: American Society of Photogrammetry and Remote Sensing. 4:248-257.

McGaughey, R.J., 1998. Techniques for visualizing the appearance of forestry operations. Journal of forestry, 96(6):9-14.

McGaughey, R.J., 1997. SVS - Stand Visualization System. Pacific Northwest Research Station USDA Forest Service, Portland. http://faculty.washington.edu/mcgoy/svs.html (Accessed: 26 April 2021).

Nagao, M., Yamada, Y., 2019. Physical effects of hinges shape on chainsaw felling direction in Japanese Cypress. International journal of forest engineering, 30(3):182-189.

Naghdi, R., Nikooy, M., Ghajar, I., Ershadifar, M., 2016. A Practical linear model for estimation of tree falling direction error in mountainous forests of northern Iran. Ecopersia, 4(3):1505-1516. 
Naemura, T., Yoshida, T., Harashima, H., 2001. 3-D computer graphics based on integral photography. Optics express, 8(2):255-262.

Naghdi, R., Bagheri, I., Taheri, A.K., Akef, M., 2007. Evaluation of assortment logging method with respect to residual damage in Shefarood Forest (North of Iran). Iranian journal of natural resources, 60(3):931-947.

Nikooy, M., Naghdi, R., Ershadifar, M., 2013. Survey of directional felling and analysis of effective factors on felling error (Case study; Iranian Caspian forests). Caspian Journal of Environmental Sciences, 11(2):177-184.

Newman, S.M., Keefe, R.F., Brooks, R.H., Ahonen, E.Q., Wempe, A.M., 2018. Human factors affecting logging injury incidents in Idaho ant the potential for real-time location-sharing technology to improve safety. Safety 4(4):43.

Shormag, Y., 2009. Economical-environmental evaluation of felling component in two logging methods (traditional and planned) (The case study of district 3. Nav-Asalem). Doctoral dissertation, MSc. Thesis, University of Guilan, Rasht, Iran.
Strong, S., Smith, R., 2001. Spatial visualization: fundamentals and trends in engineering graphics. Journal of industrial technology 18(1):1-6.

Suhurtana, S., Yuniawati, 2019. The economic and environmentally friendly tree felling techniques in natural forest. In: IOP conf. series: Earth and environmental science 359, p. 012007, IOP publishing.

Tavankar, F., Majnounian, B., Bonyad, A.E., 2013. Felling and skidding damage to residual trees following selection cutting in Caspian forests of Iran. Journal of forest science, 59(5):196-203.

Tobita, K., Nitami, T., Yoshioka, T., 2019. Factors associated with injuries related to chainsaw tree felling in Japan. International journal of forest engineering, 30(3):190-194.

Uusitalo, J., Kivinen, V.P., 2000. Implementing SmartForest forest visualization tool on PC environment. In Resource Technology '98 Nordic International Symposium on Advanced Technology in Environmental and Natural Resources. pp. 1-7. 